\title{
Cloud Computing- The Most Suitable Technology for Implementing e-Governance in Developing Countries Like India
}

\author{
N.Bindu \\ Associate Professor \\ S.N College, Cherthala
}

\begin{abstract}
E-governance is the electronic device assisted governance , which ensure reliability, accuracy, transparency and speed in government services.. The main bottle neck which adversely affect the efficiency of e-governance in developing countries, is the lack of sufficient back end support in terms of infrastructure and data base .The condition becomes more critical if there is lack of fast and efficient network connectivity and proper software support .These draw backs can be overcome by using cloud computing to a great extent .Cloud computing is the new paradigm, which will be more beneficial, incorporating accessibility, security, transparency ,low cost ,speed, convenience etc which are the key factors of a good e-governance system.
\end{abstract}

\section{General Terms}

E governance, cloud computing

\section{Keywords}

E governance ,cloud computing

\section{INTRODUCTION}

Connectivity, content, capacity and capital are the four pillars of e-governance .That means an internet connectivity, a proper database management system ,apt software and efficient user interacting devices such as mobile or PC are the basic requirements of a good e-governance system. If the e- governance efforts are to be successful, the e-governance services should reach the public even in the remote areas of the country and must be available round the clock. This any where any time implementation of e governance service demands, IT and internet penetration at the grass root level in the country. Surveys shows that IT and internet penetration is very low in India than the developed countries. This drives the e-governance efforts of India in the backward direction.

The cloud implementation reduce the heavy cost of infrastructure, database and software .While using cloud computing, the infrastructure, database management system or applications can be availed in a "leased mode" or available as "ready made" as per demand . By implementing cloud in e-governance services, the government employees can access cloud-based email and tools such as web conferencing, document sharing and real-time processing, The data storage and sharing and exchange can be done with minimal cost. In Japan," Kasumigaseki cloud" is in progress to co- ordinate the various ministry affaires and expected to complete by 2015 . Thailand, Hong Kong and Myanmar are some other countries which go for cloud computing for ensuring better e-governance. Vendors like Google Rckspace and Amazon are providing ready made platforms for hosting web based applications. Multinational companies such as .Microsoft ,IBM and HP are involved in developing SAAS based applications[2]

\subsection{Challenges of the traditional system}

The conventional manual system faces many problems. Scalability is the major problem, ie the existing system is not able to accommodate up coming modifications as per the user requirements, in an efficient manner. Frequent data base up gradation and software revival or replacement are required. The security, accountability and, development cycle of a new application are other obstacles. In the conventional system more effort and money are required for ,disaster recovery. Discarding of obsolete technology and infrastructure are other associated problems.

\section{CLOUD COMPUTING}

According to National Institute of Standards and Technology, USA (NIST), the definition of Cloud Computing is "A model for enabling ubiquitous, convenient, on demand network access to a shared pool of configurable computing resources (eg:-, networks, servers, storage, applications, and services) that can be rapidly provisioned and released with minimal management effort or service provider interaction.”. Cloud computing is dynamically scalable and virtual utilization of resources, infrastructure and services

In cloud computing technology, the operating system is available in shared basis. So the customer need not buy operating system or renew license. Updating of this will also be done automatically. If needed, the application software can also be leased. The developing cycle cost and implementation time can be avoided as ready made application software is available. Besides, the database management is also done externally with full security and back up of data .Infrastructure can also be used in this shared manner. Independent installation and repairing of communication networks including switches and routers are not needed.The Cloud computing help to avail the three services, operating system or software ,database management system and infrastructure management , without the over head of initial cost of implementation and recurring cost of maintenance. So the three key attributes of cloud computing can be counted as software as service(saas), plat forms as service (pas), and infrastructure as a service(iaas).

\subsection{Software as a service (saas)}

The customers can avail the services with out interacting with the operating system networks or database. This is the most popular type of service as it provides the services with high flexibility, high service rates ,high scalability and less maintenance .End users are the users of it. 
eg:- E-police, E-court

- Municipal Maintenance

- Water Boards, Billing, Payment Systems

- District Management Solutions

\subsection{Plat form as a service (paas)}

The customer uses the environment for hosting application programs. Actually it provides the platform on demand with out the high initial cost and maintenance cost .Application developers are the main customers of it.

Eg:- OS provisioning

- Queuing Service

- Database Services

- Middleware Services

- Workflow Services

\subsection{Infrastructure as a service (iaas)}

The customer can control the operating system and the deployed applications. Web hosting make use of this type of cloud computing. Network architects makes use of it.

\section{CLOUD COMPUTING MODELS}

There are three types of cloud computing models in implementation - public, private and hybrid.

\subsection{Private clouds}

An internal network providing services for internal users of a large organization without the restriction of bandwidth, security ,hardware or software. It is also known as internal cloud. The software applications and operating system can be shared by all members of the parent organization. It is based on virtualization technique. It promotes high level of data security. The customers have control over the IT network

\subsection{Public cloud}

Also called external cloud and provide services through the internet to the public and these services are available on pay-per-use basis.

\subsection{Hybrid cloud}

It is a combination of two or more of the above cloud models

\section{KEY FEATURES OF CLOUDS}

The cloud based e- governance has many attractive tenets. The foremost is that the services are provided on demand .The data base is accessed only when the request comes from the user .The response time is reduced very much since the cloud has great computing capacity. Next attractive feature is that the payment is on pay-per use basis. This enable to reduce the operational cost and communication cost to a great extent. The cloud can be accessed via internet on $24 \times 7$ hour basis. This feature supports any time access of citizen for the e-governance services.

The data base is not stored in the premises of the user but at the server side, which reduce the storage, maintenance and security risks . Additional cost for antivirus packages and back up storage are also reduced. .Another advantage is that the services are scalable. The modifications or additions can be accorded with an existing system without much effort. The overall cost reduction for the purchase and maintenance of the hardware and software is an important cause of attraction of e-governance clouds. The time frame required for roll out of a new service can be reduced since the platforms/ database/application environment is readily available. The asset utilization can be improved up to $70 \%$

\section{GLOBAL ACCEPTANCE OF CLOUD BASED E- GOVERNANCE.}

The cloud model acceptance can be assessed using TAM(Technology Acceptance Model ). Users acceptance can be measured as perceived usefulness, perceived ease of use ,attitude towards using etc. A global survey shows that world wide popularity of e- projects based on cloud computing is $98 \%$. The survey population supporting perceived ease of use is $94 \%$.Its popularity in terms of cost reduction and maintenance and of simplicity is $93 \%$. The survey also suggest that execution time of a new project can be reduced very much using this technology. These survey results are the strong supporting evidence in favor of the global acceptance of cloud based e- governance services

\section{IMPLEMENTATION}

Cloud computing is one of the promoting technology which will help economy of the country. The order of the different phases of implementation are the data center consolidation, virtualization ,automation and the adoption of the suitable model such as private public or hybrid cloud and implementing inter cloud deployments.

Cloud computing is a method supporting "green computing" because it use resource sharing and common data storage. The users of cloud computing can work using search engines in web , on different operating system as though they are using their own desktop environment. It also help to unify the e-governance applications, which are heterogeneous in nature to work freely as in a common platform. 


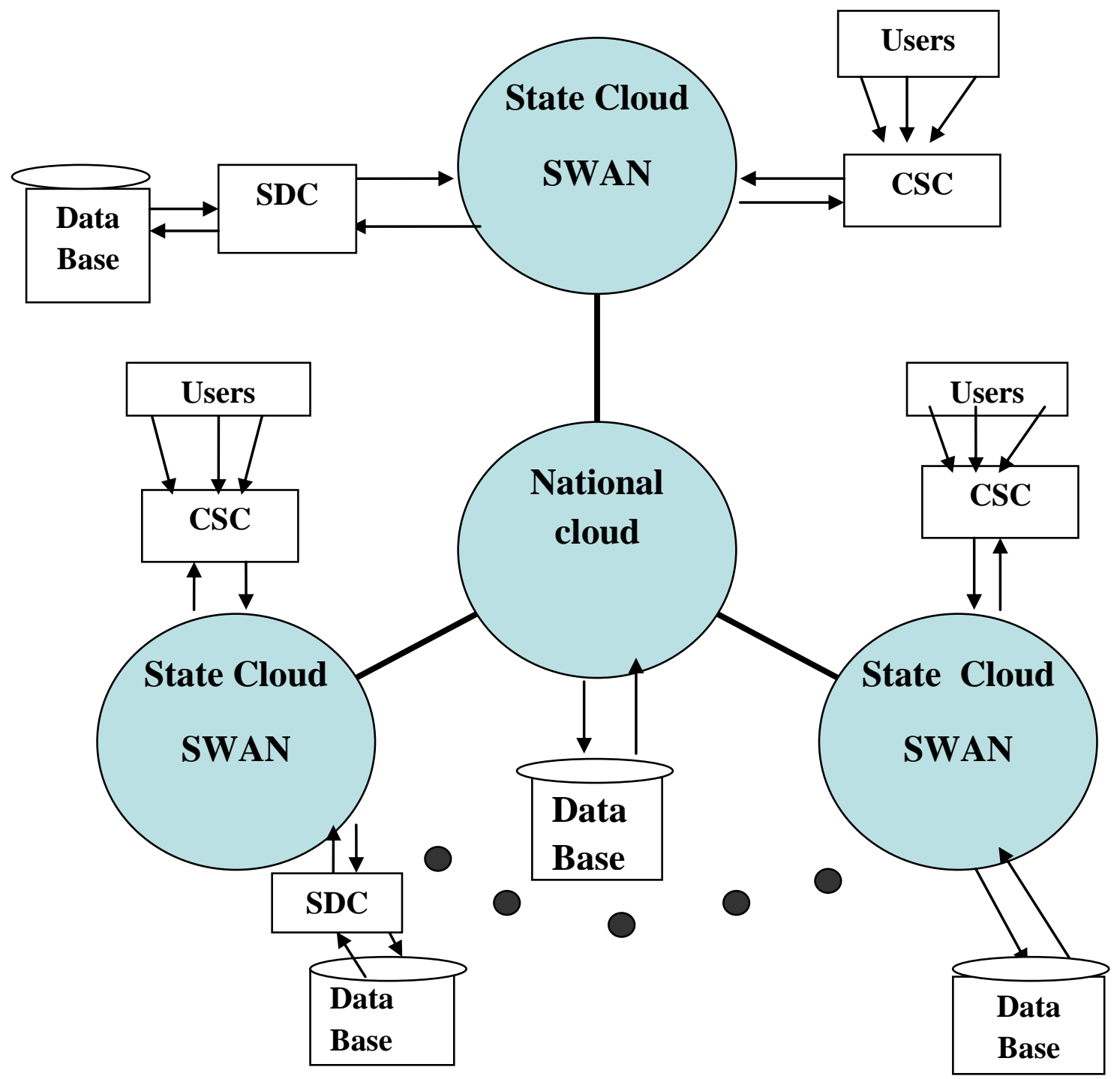

\subsection{Challenges of cloud implementation}

Cloud computing, being a strategic project, faces many challenges such as technologies, performance, security, resiliency, implementation and integration of the different platforms involved in the system. Interoperability, data migration, and transition are the main problems associated with it.

\section{INDIAN SENARIO OF CLOUD BASED E-GOVERNANCE}

India a developing country, is on its way to cloud implementation of it's e-governance projects. The structural architecture is shown in Fig 1.

Secretary for IT, ministry of IT and communications of India Reported , "A collaboration on e-governance via cloud technologies may include $90 \%$ of the citizen services, which have not yet been rolled out. It will also make project execution faster".

AADHAAR registration and providing UID numbers (project to provide unique identification numbers to the citizen) by Unique Identification Authority of India, is the first step of this approach for implementing the cloud in e-governance in Central Government of India. It is one of the MMPs (mission mode projects ) organized by NeGP ( National e Governance
Plan) of India. It necessitate the business process reengineering in the way the e-governance services are delivered

Government of India designed an architecture to implement e-governance using cloud computing called the "Meghraj" , which is an central integrated GI cloud initiative. The infrastructure implementation of SWANs, SDCs, NSDGs, SSDGs and CSCs and, other initiatives like National Data Centers (NDCs) by NIC, National Knowledge Network (NKN) and National Optical Fiber Network (NOFN) are also in progress. These initiatives will help to include governance mechanism to ensure proliferation of cloud computing in government services.

The main components of GI-cloud are Common Service Center(CSC) - e-Kiosks, State wide Area Network sSWANs- and State Data Center (SDC) .CSC and e-kiosks which are located at the citizen reach, directly interact with people providing various e-governance services. For this PPP (Private Public Partnership) model can be adopted, with reduction in the start up cost. Each of these CSCs is supposed to serve at least 1000 families especially in rural areas. This are designed as part of the "Bharath Nirman" project of NeGP 
SWANS have high processing capability and efficiency and have a capacity of $2 \mathrm{Mbps}$. The SWANs are the backbone of e-governance services in India, through blocks ,subdivisional head quarters -"gram panchayats" and municipalities by providing network for text, audio and video communication.The SDC is connected with the CSC through SWAN to form the central repository of the state, which ensure secure data storage, disaster recovery, remote management and service integration.

Considering the state level implementation of cloud in the States of India , The Jammu and Kashmir Government was first to adopt cloud computing with the help of Microsoft solutions.

\section{CONCLUSION}

The initial roll out time ,effort and cost are very much reduced in cloud based e- governance systems. It is a cost effective resource sharing technology, which support the multi perspective view of e- governance by incorporating heterogeneous resources which are geographically departed . The data security, and data transfer rate are very high in cloud computing.The cost of communication, storage and maintenance are also reduced very much. In cloud based egovernance systems ,the cost of infrastructure, operating system , application software and database management system are minimized but the speed and efficiency are maximized. .More than that by adopting Private Public Partnership model for customer service centers(CSC), the government can create job opportunities for the entrepreneurs of CSC. So for developing countries like India, cloud computing is one of the best technology for implementation of a SMART Government using e-governance at a lower cost but with maximum efficiency.

\section{RFERENCES}

[1] Dr.Ashish Rastogi,,"A model based approach to implement cloud computing in e-governance",
International journal of Computer Applications Volume9-no 7, November $2010,0975-8887$

[2] N.Vijayakumar, "Role of ICT in e-Governance Impact of cloud computing in Driving New initiatives"., SETLabs Briefings Vol 9 no 2,2011 .

[3] Dr. R.Siva Rama Prasad, Veera Raghava Rao Atukuri, "Cloud Computing Technology for Effective eGovernance “, International Journal of Computer Science and Information Technologies, Vol. 3 (1), 2012,32413244, ISSN 0975-9646

[4] K.Mukharjee, G.SAhoo, "Cloud computing -future framework for e-governance ", International journal of Computer Applications (0975-8887)Volume-7 no-7 October 2010

[5]. Rashmi Sharma, Anurag Sharma , Dr. U.S Pandey, Dr..Mukherjee, "E-Governance: A Successful Implementation of Government Policies using Cloud Computing “, International Conference on Web Services Computing (ICWSC) 2011 ,Proceedings of International Journal of Computer Applications® (IJCA)

[6] . Vikram Kumar , “Cloud Enables Better Governance,” , Cisco India SAARC, on web -http://www.cisco.com /web/IN/about/network/governance.html

[7]. S. Madhava Reddy, E. Mruthyunjaya ,J. Srikanth "Architecture Supporting e-Governance", International Journal of Advanced Research in Computer Science and Software Engineering, Volume 2, Issue 8, August 2012 ISSN: 2277 128X

[8].Subhash Chander1 and Ashwani Kush ," UID, Cloud Computing \& E-Governance" , Proceedings of the 5th National Conference;-Computing For Nation Development, March,2011, Bharati Vidyapeeth's Institute of Computer Applications and Management, New Delhi. ISSN 0973-7529 ISBN 978-93-80544-00-7 